As-Syifaa Jurnal Farmasi Desember 2020;12(2):84-90.

ISSN : 2502-9444 (electronic); 2085-4714 (printed)

Journal Homepage : http://jurnal.farmasi.umi.ac.id/index.php/as-syifaa

\title{
PROFIL SOSIODEMOGRAFI DAN TERAPI ANTIRETROVIRAL PADA PASIEN HIV/AIDS RAWAT JALAN RSUD RADEN MATTAHER JAMBI PERIODE TAHUN 2017-2018
}

\author{
Jelly Permatasari, Muhammad Budi, Indri Meirista \\ Program Studi Farmasi, STIKES Harapan Ibu Jambi \\ Email: muhammmadbudii@gmail.com
}

\begin{abstract}
As a result of the decline in the immune system it is very susceptible to various diseases (opportunistic Infections) that can be prevented by the presence of antiretroviral therapy with various complications. Sociodemographic Profile is a human picture related to the purpose of the study, Sociodemographic research in HIV / AIDS patients is still rarely found, therefore Sociodemographic Profile is important to know as a basis for information that can be used to prevent transmission of HIV / AIDS. The purpose of this study was to determine the Sociodemographic Profile and ARV therapy in outpatient HIV / AIDS patients at Raden Mattaher Jambi Hospital in the 2017-2018 period. This research method is descriptive by retrospectively collecting data from medical record data. The results showed in the Age group 26-35 years (41.94\%), Male sex (70.97\%), the last high school education (61.29\%), Employee / Private employment history (54.84\%), based on the highest transmission Heterosexual (84.95\%), with Marital marital status (83.87\%), based on the highest HIV / AIDS status namely HIV (94.62\%). Based on ARV therapy, most combinations of Efavirens + Lamivudin + Tenofovir (59.14\%).
\end{abstract}

Key words: Sociodemographic profile, HIV / AIDS, ARV therapy.

\section{PENDAHULUAN}

Tingginya angka penderita HIV dan pesatnya pertumbuhan jumlah penderita AIDS tidak terlepas dari faktor sosial didalam kehidupan masyarakat. WHO menyatakan tren pertumbuhan jumlah penderita AIDS yang tinggi pada wilayah tertentu, misalnya pada Negara di Afrika bagian sub-sahara, sebesar $71 \%$ penderita HIV/AIDS secara global terdapat pada wilayah ini. ${ }^{1}$

Berdasarkan data Kemenkes jumlah kasus baru HIV dari tahun 2015-2017 di provinsi Jambi menunjukan tren yang naik turun. Di tahun 2015 terdapat 148 kasus, tahun 2016 terdapat 215 kasus dan tahun 2017 terdapat 185 kasus. Kasus HIV dan AIDS terbanyak berada dikota jambi dengan jumlah kasus masing-masing yaitu 68 kasus HIV dan AIDS 43 kasus. $^{2}$ Gambaran kasus baru HIV positif tahun 2016 tertinggi terjadi pada kelompok Usia 25-49 tahun (69,3\%). ${ }^{3}$

Berdasarkan hasil penelitian sebelumnya di RSUD dr. Pirngadi Medan pada tahun 2015 menunjukkan karakteristik Sosiodemografi tertinggi penderita rawat jalan HIV/AIDS pada kelompok Usia 30-39 tahun jenis kelamin Laki-Laki (34,8\%), pendidikan terakhir SLTA/Sederajat $(67,8 \%)$, pekerjaan Wiraswasta (42,1\%), status pernikahan Menikah (46,7\%), dan transmisi Heteroseksual $(64,3 \%) .{ }^{4}$ Karakteristik Sosiodemografi pasien HIV/AIDS dengan Kandidiasis Orofaringeal, persentase tertinggi terdapat jenis kelamin Laki-Laki (69\%), kelompok Usia terbanyak 3039 tahun $(40,48 \%)$, tingkat pendidikan SD $(30,95 \%)$, pekerja buruh dan pegawai Swasta $(21,43 \%)$, dan status pernikahan yang sudah Menikah $(88,09 \%) .^{5} \quad$ Pada penelitian 
sebelumnya mengenai pengobatan ARV (Antiretroviral) yang paling banyak digunakan adalah kombinasi AZT (Zidovudine) + 3TC (Lamivudine) + NVP (Nevirapine) yaitu sebanyak 22 pasien dengan persentase $(44 \%) .{ }^{6}$ Beberapa pandangan orang dan kebiasaan dimasyarakat juga berkontribusi dalam pesatnya pertumbuhan penderita HIV/AIDS. Langkah-langkah pencegahan penularan HIV juga harus mempertimbangkan aspek sosial budaya di masyarakat. Hal ini menunjukan bahwa Profil Sosiodemografi merupakan aspek penting untuk diikut sertakan dalam kajian ilmiah dalam rangka mengendalikan suatu penyakit.

\section{METODE PENELITIAN}

Penelitian ini merupakan penelitian deskriptif melalui penelusuran data yang bersifat retrospektif terhadap data rekam medis pasien HIV/AIDS berdasarkan Profil Sosiodemografi dan Terapi Antiretroviral di RSUD Raden Mattaher Jambi Periode Tahun

\section{HASIL DAN PEMBAHASAN}

\section{Profil Sosiodemografi}

Tabel 1. Karakteristik Berdasarkan Usia Pasien Tahun 2017-2018

\begin{tabular}{cccc}
\hline No. & Usia & Jumlah & Persentase \\
\hline 1 & $17-25$ tahun & 14 & 15,05 \\
2 & $26-35$ tahun & 39 & 41,94 \\
3 & $36-45$ tahun & 27 & 29,03 \\
4 & $46-55$ tahun & 11 & 11,83 \\
5 & $56-65$ tahun & 2 & 2,15 \\
\hline & Total & $\mathbf{9 3}$ & $\mathbf{1 0 0 , 0 0}$ \\
\hline
\end{tabular}

Berdasarkan usia kategori usia dibagi menjadi beberapa kategori yaitu masa remaja akhir 17-25 tahun, dewasa awal 26 - 35 tahun, dewasa akhir 36-45 tahun, lansia awal 46-55 tahun dan manula $>65$ tahun. $^{7}$ Berdasarkan hasil penelitian yang telah dilakukan di RSUD Raden Mattaher Jambi didapatkan data rekam medik pasien HIV/AIDS tahun 2017 dan 2018 yang terbanyak pada rentang usia 26-35 tahun
2017-2018. Sampelnya semua pasien HIV/AIDS rawat jalan yang terdaftar di RSUD Raden Mattaher Jambi. Variabel pada penelitian ini adalah Profil Sosiodemografi berdasarkan Usia, Jenis Kelamin, Pendidikan, Pekerjaan, Transmisi, Status Pernikahan, Status HIV/AIDS, dan Terapi Antiretroviral berdasarkan data catatan rekam medis pada tahun 2017-2018. Data yang diperoleh dalam penelitian ini bersumber dari data rekam medis dan catatan medis di poli VCT (Voluntary Counseling and Testing), untuk pasien HIV/AIDS periode tahun 2017-2018 di instalasi rawat jalan RSUD Raden Mattaher Jambi. Data yang diperoleh dikelompokan berdasarkan kategori masing-masing menurut karakteristik Sosiodemografi dan Pengobatan. Selanjutnya dipersentasekan dalam bentuk tabel. Data dianalisis secara deskriptif untuk mengetahui Profil Sosiodemografi dan Terapi Antiretroviral pasien HIV/AIDS rawat jalan di RSUD Raden Mattaher Jambi. 
and AIDS) tahun 2016 pada penderita

HIV/AIDS didunia dimana kelompok usia paling banyak terinfeksi pada kelompok usia produktif yaitu usia 20-40 tahun. ${ }^{10} \mathrm{Hal}$ ini terjadi karena pada kelompok usia produktif ini merupakan usia aktivitas tinggi yang melakukan seks berisiko yang tidak aman, penyalahgunaan obat-obatan terlarang, menggunakan narkoba suntik, yang merupakan resiko tinggi tertular HIV. ${ }^{11}$

Tabel 2. Karakteristik Berdasarkan Jenis Kelamin Pasien Tahun 2017-2018

\begin{tabular}{cccc}
\hline No. & Jenis Kelamin & Jumlah & Persentase \\
\hline 1 & Laki-Laki & 66 & 70,97 \\
2 & Perempuan & 27 & 29,03 \\
\hline & Total & $\mathbf{9 3}$ & $\mathbf{1 0 0 , 0 0}$
\end{tabular}

Berdasarkan jenis kelamin hasil penelitian yang telah dilakukan di RSUD Raden Mattaher Jambi didapatkan data rekam medik tahun 2017 dan 2018 terbanyak yaitu pada jenis kelamin laki-laki dengan persentase $70,97 \%$. Sedangkan pada perempuan menunjukan dengan persentase $29,03 \%$. Hal ini sejalan dengan penelitian yang telah dilakukan di RSPI Prof. Dr. Sulianti Saroso yang menyatakan bahwa jumlah penderita lakilaki 92 pasien dengan persentase $74,19 \%$ lebih banyak dibandingkan perempuan 32 pasien dengan persentase $25,81 \% .{ }^{12}$ Pada penelitian sebelumnya juga menunjukan persentase jenis kelamin terbanyak yaitu pada laki-laki sebanyak 72 pasien dengan persentase $64,9 \%$, sedangkan pada perempuan terdapat 39 pasien dengan persentase $35,1 \%{ }^{13}$ Tingginya distribusi laki-laki yang menderita HIV/AIDS diasumsikan karena banyaknya lakilaki yang melakukan faktor resiko seperti berhubungan seksual menyimpang berisiko, seperti berhubungan seks bebas atau bergantiganti pasangan dan berhubungan seks dengan sesama jenis atau homoseksual serta penggunaan obat-obat terlarang dengan alat suntik yang tidak steril.

Tabel 3. Karakteristik Berdasarkan Pendidikan Pasien Tahun 2017-2018

\begin{tabular}{cccc}
\hline No. & Pendidikan & Jumlah & Persentase \\
\hline 1 & Tidak sekolah & 5 & 5,38 \\
2 & SMP & 8 & 8,60 \\
3 & SMA & 57 & 61,29 \\
4 & Akademik & 16 & 17,20 \\
5 & Perguruan tinggi & 7 & 7,53 \\
\hline & Total & $\mathbf{9 3}$ & $\mathbf{1 0 0 , 0 0}$ \\
\hline
\end{tabular}

Berdasarkan pendidikan terakhir jumlah penderita HIV/AIDS di tahun 2017 dan 2018 terbanyak berasal dari lulusan SMA dengan persentase $61,29 \%$ diikuti dengan pendidikan Akademik dengan persentase $17,20 \%$. Penelitian ini sejalan dengan penelitian sebelumnya yang dilakukan di Klinik CST RSJD yang menunjukan hasil terbanyak yaitu pada SMA dengan persentase $62 \% .^{6}$ Tingkat pendidikan seseorang berpengaruh terhadap kemampuan menyerap dan menerima informasi kesehatan. Selain itu pendidikan juga berpengaruh terhadap perilaku yang lebih baik. Seseorang yang mempunyai tingkat pendidikan akan mempunyai wawasan yang luas sehingga dapat menjadi teladan. ${ }^{13}$ 
Profil Sosiodemografi dan Terapi Antiretroviral Pada Pasien HIV/AIDS Rawat Jalan RSUD Raden Mattaher Jambi Periode Tahun 2017-2018

Hal ini sesuai dengan pernyataan nyoko yang menyebutkan bahwa tingkat pengetahuan seseorang dipengaruhi oleh tingkat pendidikan.

Sehingga dengan pendidikan yang tinggi seharusnya seseorang dapat mencegah diri dari faktor resiko penularan HIV. Pada kenyataanya tidak selamanya tingkat pendidikan yang rendah akan menyebabkan perilaku kesehatan seseorang menjadi buruk. Seseorang dapat memperoleh informasi dan pengalaman yang dapat menjadi sumber pembelajaran mereka. ${ }^{12}$

Tabel 4. Karakteristik Berdasarkan Pekerjaan Pasien Tahun 2017-2018

\begin{tabular}{cccc}
\hline No. & Pekerjaan & Jumlah & Persentase \\
\hline 1 & Karyawan/Swasta & 51 & 54,84 \\
2 & IRT & 19 & 20,43 \\
3 & PNS & 7 & 7,53 \\
4 & Tidak Bekerja & 7 & 7,53 \\
5 & Petani & 6 & 6,45 \\
6 & PSK & 3 & 3,23 \\
\hline & Total & $\mathbf{9 3}$ & $\mathbf{1 0 0 , 0 0}$ \\
\hline
\end{tabular}

Berdasarkan pekerjaan hasil yang dilakukan di RSUD Raden Mattaher Jambi penelitian tahun 2017 dan 2018 menunjukan distribusi berdasarkan pekerjaan terbanyak yaitu karyawan/swata dengan persentase 54,84\%, diikuti IRT (Ibu Rumah Tangga) dengan persentase $20,43 \%$. Hal ini sejalan dengan penelitian sebelumnya yang dilakukan di RSUP Dr. Kariadi Semarang menunjukan distribusi pekerjaan terbanyak yaitu pegawai swasta dengan persentase $21,43 \%$, diikuti urutan kedua IRT (Ibu Rumah Tangga) dengan persentase $19,05 \%^{5}$, serta pada hasil penelitian sebelumnya yang dilakukan di RSUD Umbu Rara Meha di Nusa Tenggara Timur didapat hasil yang berbeda yaitu distribusi pekerjaan terbanyak sebagai petani dengan persentase $48,6 \%$, diikuti swasta dengan persentase $27,9 \%{ }^{13} \quad$ Teori segitiga epidemiologi menyatakan suatu penyakit menular dipengaruh oleh host, agent dan lingkungan. ${ }^{14}$ Berdasarkan teori tersebut lingkungan dalam hal ini masuk pekerjaan dimana lingkungan pekerjaan dapat mempengaruhi kejadian sakit seseorang. ${ }^{13}$

Tabel 5. Karakteristik Berdasarkan Transmisi Pasien Tahun 2017-2018

\begin{tabular}{cccc}
\hline No. & Transmisi & Jumlah & Persentase \\
\hline 1 & Heteroseksual & 79 & 84,95 \\
2 & NAPZA Suntik & 8 & 8,60 \\
3 & Homoseksual & 4 & 4,30 \\
4 & Tatto & 1 & 1,08 \\
5 & Tranfusi darah & 1 & 1,08 \\
\hline & Total & $\mathbf{9 3}$ & $\mathbf{1 0 0 , 0 0}$
\end{tabular}

Berdasarkan transmisi hasil penelitian yang telah dilakukan di RSUD Raden Mattaher Jambi tahun 2017 dan 2018 menunjukan angka penularan terbanyak yaitu heteroseksual dengan persentase $84,95 \%$. Penelitian ini sejalan dengan penelitian sebelumnya yang dilakukan di RSPI Prof. Dr. Sulianti Saroso menyatakan angka penularan terbanyak 
Profil Sosiodemografi dan Terapi Antiretroviral Pada Pasien HIV/AIDS Rawat Jalan RSUD Raden Mattaher Jambi Periode Tahun 2017-2018

heteroseksual dengan persentase $86,29 \%$.

Faktor resiko dengan penularan heteroseksual menunjukan bahwa pola aktivitas seksual dari seorang pasien adalah berganti-ganti pasangan. Kegiatan seksual berganti-ganti pasangan yang tidak diimbangi dengan kesadaran berperilaku seks secara aman menjadi faktor utama resiko penularan infeksi HIV. $^{12}$

Tabel 6. Karakteristik Berdasarkan Status Pernikahan Pasien Tahun 2017-2018

\begin{tabular}{cccc}
\hline No. & Status Pernikahan & Jumlah & Persentase \\
\hline 1 & Menikah & 78 & 83,87 \\
2 & Belum Menikah & 12 & 12,90 \\
3 & Janda/Duda & 3 & 3,23 \\
\hline & Total & $\mathbf{9 3}$ & $\mathbf{1 0 0 , 0 0}$ \\
\hline
\end{tabular}

Berdasarkan status pernikahan hasil penelitian yang telah dilakukan di RSUD Raden Mattaher Jambi tahun 2017 dan 2018 menunjukan status terbanyak yaitu yang sudah menikah dengan persentase $83,87 \%$. Penelitian ini sejalan dengan penelitian sebelumnya yang dilakukan di RSUP Dr. Kariadi Semarang menyatakan yang sudah menikah paling banyak dengan persentase $88,09 \% .^{5}$ Dan pada penelitian yang dilakukan di RSPI Prof. Dr. Sulianti Saroso didapat angka terbanyak yaitu yang sudah menikah dengan persentase $75,81 \%$. Status menikah pada pasien memperbesar kemungkinan terjadinya resiko transmisi infeksi HIV melalui kontak seksual. Kemudian dari suatu pernikahan akan mendapatkan keturunan yang akan meningkatkan resiko infeksi HIV dari ibu ke anak. $^{12}$

Tabel 7. Karakteristik Berdasarkan Status HIV/AIDS Pasien Tahun 2017-2018

\begin{tabular}{cccc}
\hline No. & Status HIV/AIDS & Jumlah & Persentase \\
\hline 1 & HIV & 88 & 94,62 \\
2 & HIV \& AIDS & 5 & 5,38 \\
\hline & Total & 93 & $\mathbf{1 0 0 , 0 0}$ \\
\hline
\end{tabular}

Berdasarkan status HIV/AIDS di RSUD Raden Mattaher Jambi tahun 2017 dan 2018 menunjukan angka terbanyak yaitu HIV dengan persentase $94,62 \%$. Penyebabnya sudah banyak terjadi di semua kalangan

\section{Pengobatan HIV/AIDS}

Tabel 8. Terapi Antiretroviral Pasien Tahun 2017-2018

\begin{tabular}{cccc}
\hline No. & Terapi Antiretroviral & Jumlah & Persentase \\
\hline 1 & Efavirens + Lamivudin + Tenofovir & 55 & 59,14 \\
2 & Lamivudin + Zidovudine + Nevirapine & 16 & 17,20 \\
3 & Tenofovir + Lamivudin + Nevirapine & 13 & 13,98 \\
4 & Lamivudin + Zidovudine + Efavirens & 9 & 9,68 \\
\hline & Total & $\mathbf{9 3}$ & $\mathbf{1 0 0 , 0 0}$ \\
\hline
\end{tabular}

diakarenakan kurangnya pengetahuan tentang HIV/AIDS, yang meliputi Pengertian, Penyebab, Cara Penularan, Pencegahan, dan Pengobatan (Terapi) HIV/AIDS. 
Berdasarkan terapi Antiretroviral hasil penelitian yang telah dilakukan di Raden Mattaher Jambi tahun 2017 dan 2018 menunjukan terapi yang paling banyak digunakan adalah Atripla yaitu kombinasi EFZ + 3TC + TDF dengan jumlah 55 pasien dan persentase $59,14 \%$, diikuti $\mathrm{D} / \mathrm{N}$ kombinasi $3 \mathrm{TC}$ + AZT + NVP dengan jumlah 16 pasien dan persentase $17,20 \%, \mathrm{~T} / \mathrm{H} / \mathrm{N}$ kombinasi TDF + $3 T C+N V P$ dengan jumlah 13 pasien dan persentase $13,98 \%$, dan D/E kombinasi 3TC + AZT + EFZ dengan jumlah 9 pasien dan persentase $9,68 \%$. Berdasarkan pedoman nasional tentang Tatalaksana Klinis Infeksi HIV dan Terapi Antiretroviral yang menyatakan jenis terapi ARV lini pertama harus berisi 2 NRTI + 1 NNRTI yaitu TDF + 3TC (atau FTC) + EFZ. ${ }^{15} 2$ golongan NRTI yaitu 3TC, TDF dan 1 NRTI yaitu EFZ. Hal ini sejalan dengan penelitian lain bahwa kombinasi terapi antiretroviral EFZ + 3TC + TDF juga banyak digunakan untuk terapi pasien HIV yang dilakukan di RSUD Dr. Soebandi dengan persentase $91,8 \%{ }^{16}$, serta sejalan juga dengan penelitian sebelumnya yang dilakukan di RSPI Prof. Dr. Sulianti Saroso yang menyatakan penggunaan terbanyak sebagai terapi ARV kombinasi EFZ + 3TC + TDF dengan persentase $73,68 \%$, dikuti $3 T C+A Z T+N V P$ dengan persentase $17,90 \%$, Kombinasi AZT (Zidovudine) jarang digunakan karena efeknya yang dapat menyebabkan anemia, dan dilakukanya penelitian mengenai efek samping dari kombinasi EFZ + 3TC + TDF yang menunjukan hasil persentase $68,42 \%$ dengan reaksi ringan, seperti sakit kepala, sukar tidur, dan mual/muntah. Hal ini disebabkan karena efek dari obat EFZ (Efavirens) yang menyerang pada gangguan SSP (Sistem Saraf Pusat). Berdasarkan data pengganti regimen menunjukan penggantian regimen terapi hanya $5,27 \%$, hal ini karena timbulnya reaksi obat yang masih bisa diterima efek sampingnya. ${ }^{12}$ Oleh karena itu obat Atripla merupakan obat dengan tiga zat aktif yang terdapat dalam satu bentuk sediaan kaplet dengan pemakaian satu kali sehari sehingga regimen terapi ini lebih praktis, sehingga banyak direkomendasikan oleh dokter.

\section{KESIMPULAN}

Berdasarkan hasil penelitian Profil Sosiodemografi dan Terapi Antiretroviral pada pasien HIV/AIDS di RSUD Raden Mattaher Jambi dapat ditarik kesimpulan yaitu berdasarkan Profil Sosiodemografi menyatakan bahwa pasien yang terinfeksi HIV/AIDS yang terbanyak rentang Usia 26-35 tahun. Berdasarkan Jenis Kelamin yang terbanyak berjenis kelamin Laki-Laki. Berdasarkan riwayat Pendidikan terbanyak terinfeksi SMA. Berdasarkan riwayat Pekerjaan terbanyak terinfeksi Swasta. Berdasarkan Transmisi yang paling banyak terinfeksi terdapat pada Heteroseksual. Berdasarkan Status Perkawinan yang paling banyak terinfeksi dikalangan yang sudah Menikah. Berdasarkan Status HIV/AIDS yang terbanyak terinfeksi HIV. Berdasarkan Pengobatan HIV/AIDS menyatakan bahwa obat yang digunakan pasien yang terinfeksi HIV/AIDS terbanyak yaitu Atripla kombinasi Efavirens + Lamivudin + Tenofovir.

\section{DAFTAR PUSTAKA}

1. World Health Organization. World Health Organization HIV/AIDS. Retrieceved September 25, 2017.

2. Fitrianingsih, Ersa CB, Desti I, Wirdayanti. Gambaran Karakteristik Pasien HIV Di Poli Rawat Jalan RSUD Raden Mattaher Jambi. Jurnal IImiah IImu Terapan Universitas Jambi. 2019; 3(1): 54-60. 
3. Kemenkes RI. Profil Kesehatan Indonesia Tahun 2016. Jakarta, 2016.

4. Purba R, Sarumpaet SM. Karakteristik Penderita HIV/AIDS Yang Berobat Jalan Di RSUD Dr Pirngadi Medan Tahun 2015. Jurnal USU: $1-10$

5. Sofro Udji MA, Angita I, Isbandoro B. Karakteristik Pasien HIV/AIDS dengan Kandidiasis Orofaringeal Di RSUP Dr. Kariadi Semarang. Medica Hospitalia: Journal of Clinical Medicine.2013; 1(3): 164-68.

6. Safitri C. Profil Karakteristik Pada Pasien HIV/AIDS Dengan Terapi Antiretroviral Di Klinik CST RSJD Sungai Bangkong Pontianak. Jurnal Mahasiswa Farmasi Fakultas Kedokteran UNTAN. 2019; 4(1).

7. Taroreh FF, Joseph WBS, Kawatu PAT. Hubungan Antara Umur Dan Masa Kerja Dengan Keluhan Musculoskeletal Pada Kusir Bendi Di Kota Tomohon. KESMAS. 2017; 6(3): 1-10.

8. Superkertia IGME, Astuti IW, Lestari MPL. Hubungan Antara Tingkat Spiritualitas Dengan Tingkat Kualitas Hidup Pada Pasien HIV/AIDS Di Yayasan Spirit Paramacitta Denpasar. COPING. 2016; 4(1): 49-53.

9. Septiansyah E, Fitriangga A, Irsan A. Faktor-Faktor Yang Berhubungan Dengan Kepatuhan Pasien HIV / AIDS Dalam Menjalani Terapi Antiretroviral Di Care
Support Tratment Rumah Sakit Jiwa Sungai Bangkong Pontianak. Jurnal Cerebellum. 2018; 4(1): 956-970.

10. Joint United Nations Programme on HIV and AIDS (UNAIDS). Global report: UNAIDS report on the global AIDS epidemic 2016. Geneva: Joint United Nations Program on HIV/AIDS., 2016.

11. Kemenkes RI. Profil Kesehatan Indonesia Tahun 2017. Jakarta., 2017.

12. Yelfi A, Nugroho SA, Tantri ND. Karakteristik Sosiodemografi, Klinis, dan Pola Terapi Antiretroviral Pasien HIV/AIDS di RSPI Prof. Dr. Sulianti Saroso Periode Januari-Juni 2016. Pharmacy: Jurnal Farmasi Indonesia. 2018; 15(1): 72-89.

13. Nyoko, Octavianus $Y$, Hara MK, Abselian UP. Karakteristik Penderita HIV/AIDS Di Sumba Timur Tahun 2010-2016. Jurnal Kesehatan Primer. 2016; 1(1) :4-15.

14. Dr. Irwan. Epidemiologi Penyakit Menular. Yogyakarta: CV. Absolute Media., 2017.

15. Kemenkes RI. Tatalaksana Klinis Infeksi HIV dan Terapi Antiretroviral. Jakarta., 2011.

16. Nuraini A, Afifah $M$, Prihwanto BS. Pengaruh Faktor Klinik dan Pengobatan Terhadap Keberhasilan Terapi Tuberkulosis Pada Pasien HIV-TB di Jember.e-jurnal Kesehatan. 2017; 5(2). 